\title{
OSSIFICATION OF THE MENINGES *
}

CHARLES A. MCKENDREE, A.B., M.D.

Associate in Neurology, Columbia University

AND

HARRY M. IMBODEN, M.D.

Visiting Physician to the Roentgen-Ray Department, Presbyterian Hospital NEW YORK

"Death seems to be the only object of hope and consolation in all such deplorable cases, as the unhappy patient must be frequently subject to pains, spasms, and occasional dereliction of the faculties, both of body and mind, which . . . are likely to terminate . . . in palsy, mania, idiotism or other maladies more grievous than death itself." Such was the comment of Dr. J. Smith ${ }^{1}$ in a letter, written in 1780 , to William Hunter, referring to ossification of the meninges, which he had discovered, postmortem, in a recent case. In that period of medical practice, such a pathologic finding sufficed to explain the most grotesque and most divergent clinical findings. Paralyses, chorea, epilepsy, a wide range of psychotic manifestations and feeble-mindedness, constitute a few of the maladies to which Dr. Smith referred. Many case reports were published in an attempt to interpret countless symptoms, the true nature of which the medical man of that period could not otherwise explain, because of what we now know to have been insufficient knowledge of anatomic and physiologic relationship.

Again, the accidental discovery of bony tumors, plaques and extensive ossification of the meninges in persons who had certainly died of systemic disease, and who had not previously manifested cerebral symptoms, led to widespread discussion of the subject.

The literature shows an active interest on the part of medical men, especially during the first half of the nineteenth century; but it is most probable that the celebrated lectures of Virchow, insisting on the benign character of these pathologic changes, checked the impetus of pseudoscientific interpretation, and, as a result, interest lagged, and reported cases since 1870 have been comparatively few. Whether the percentage of occurrence has been actually less, or the presence of meningeal ossification has been observed and noted as unimportant is a matter of question. The fact is that it is most difficult to find any mention of the subject in our leading textbooks on neurology and

* Read at the forty-seventh annual meeting of the American Neurological Association, Atlantic City, N. J., June, 1921.

1. Smith, J.: The History of an Extraordinary Affection of the Brain, Med. Obs. Soc. Phys., London 6:180-185, 1784. 
pathologic anatomy. Oppenheim mentions it only to state that ossification is common, and may be extensive, even to the point of enveloping the brain, but that it has no clinical significance.

While none of us today has the temerity even to suggest that bony transformation of the meninges may produce the cerebral mischief mentioned, we are impressed with the possible significance of this finding in certain cases. A careful study of the literature has revealed most remarkable and almost unbelievable osseous changes. While, for the most part, the pathologic reports may be accepted as trustworthy, it is evident that the conclusions in many instances were incorrect. Frequently such findings as milky exudates, hemorrhagic areas, "preternatural congestions," areas of softening, free blood and even pus in the ventricles, indicate at once the probability that the ossified areas were only coincidental changes.

But, in the broader aspect, it is almost certain that the location, extent, depth and other characteristics of osteophytic processes described in the early literature would present to us, in isolated instances, definite signs of intracranial disturbance. Today we are quite aware of the manifest symptoms that may arise from a small irritative lesion of the cerebral cortex or the overlying meninges, especially in certain areas. On the other hand, we are aware that extensive infiltration of the brain substance may occur without giving rise to significant symptoms. Hence it may be of interest to summarize briefly the pathologic changes that have been described to date, in the earnest hope that, in the light of our more advanced methods of examination and interpretation, their occasional clinical importance may be noted.

The falx cerebri easily assumes first place as the most common site. The regions of the dura alongside the superior longitudinal sinus, and the tentorium are next in frequency of occurrence. All areas of the convexity, however, may be affected.

The dura is frequently involved alone, or may be the seat of a process which involves the other tunics as well. Again, ossification may have its origin in the pia-arachnoid, leaving the dura free.

The meninges may be the seat of isolated plaques, minute and multiple, or of clusters, irregularly placed or united to form in plates extending anteroposteriorly the length of the brain and laterally over the convexity so that the brain is practically encased in a bony sheath.

The osseous formations may be pyramidal in shape and multiple, and the convolutions are seen to be molded exactly to the opposing surfaces. Solid masses of bone, the size of a hazelnut and larger, may develop from the inner surface of the pia-arachnoid and become embedded in the cortical substance between the convolutions. These have been invariably associated with corresponding changes in the meninges overlying them. 
The thickness of the specimens reported varies between a millimeter to a centimeter, perhaps in the same plaque. The outer surfaces are invariably smooth and glistening, while the inner surfaces are always rough and jagged. Stalactite processes are common, and may be so pointed that the outer tunics are pierced and the cortex invaded for a considerable distance. This is a peculiarly significant feature from the standpoint of symptomatology.

The meninges involved usually manifest a congestion of the vessels, and, especially in those cases in which there has been a history of trauma, adhesions are frequently observed.

A theoretical discussion of the relationship of calcification to ossification will not be entered into; nevertheless it is well to note that many of the published cases have demonstrated true bony changes. We know that areas of the meninges or brain substance that have become calcified through the medium of extravasated blood due to trauma or from any other cause may become ossified. We know that in the presence of osteoblasts such changes may take place in other parts of the body, such as the heart, kidney, pleura and eyeball. Whether such metaplasia in the brain and its coverings is made more readily possible because of the embryologic functions of the dura, or whether through a specific action on connective tissue cells calcium leads to ossification, are questions apart from the purpose of this communication.

Despite the absence of postmortem confirmation, the following case, representing extensive ossification of the meninges, with certain evidences of focal irritation or pressure, is worthy of report. To our knowledge, it embodies the first attempt to study, according to our present day methods, the clinical manifestations of such a pathologic process.

\section{REPORT OF A CASE}

History:-Mrs. X., aged 49, married, born in the United States, a housewife, came under observation in March, 1921, through the courtesy of Dr. Evan Evans. She complained of attacks of vomiting, severe headaches, insomnia, languor, and lack of endurance. These symptoms had been particularly prominent for nine or ten years. The patient believed that with the exception of the vomiting, her condition had become gradually worse.

Her mother died at 70 , having had trigeminal neuralgia, pernicious anemia and some cardiac disturbance. Her father died of "rheumatism" combined with anxiety. Two brothers were well, and her husband and two children were quite well. There was no history of a similar affection in the collateral branches. As a child the patient was never very robust. She was always considered anemic, and between the ages of 12 and 14 had had severe "fainting spells" but no convulsions. She had had all of the usual childhood diseases, including measles in a particularly serious form. Tonsillotomy was performed during adolescence. Menses appeared at the age of 13 and had always been regular, rather profuse and painful. An attempted curettage and cervical 


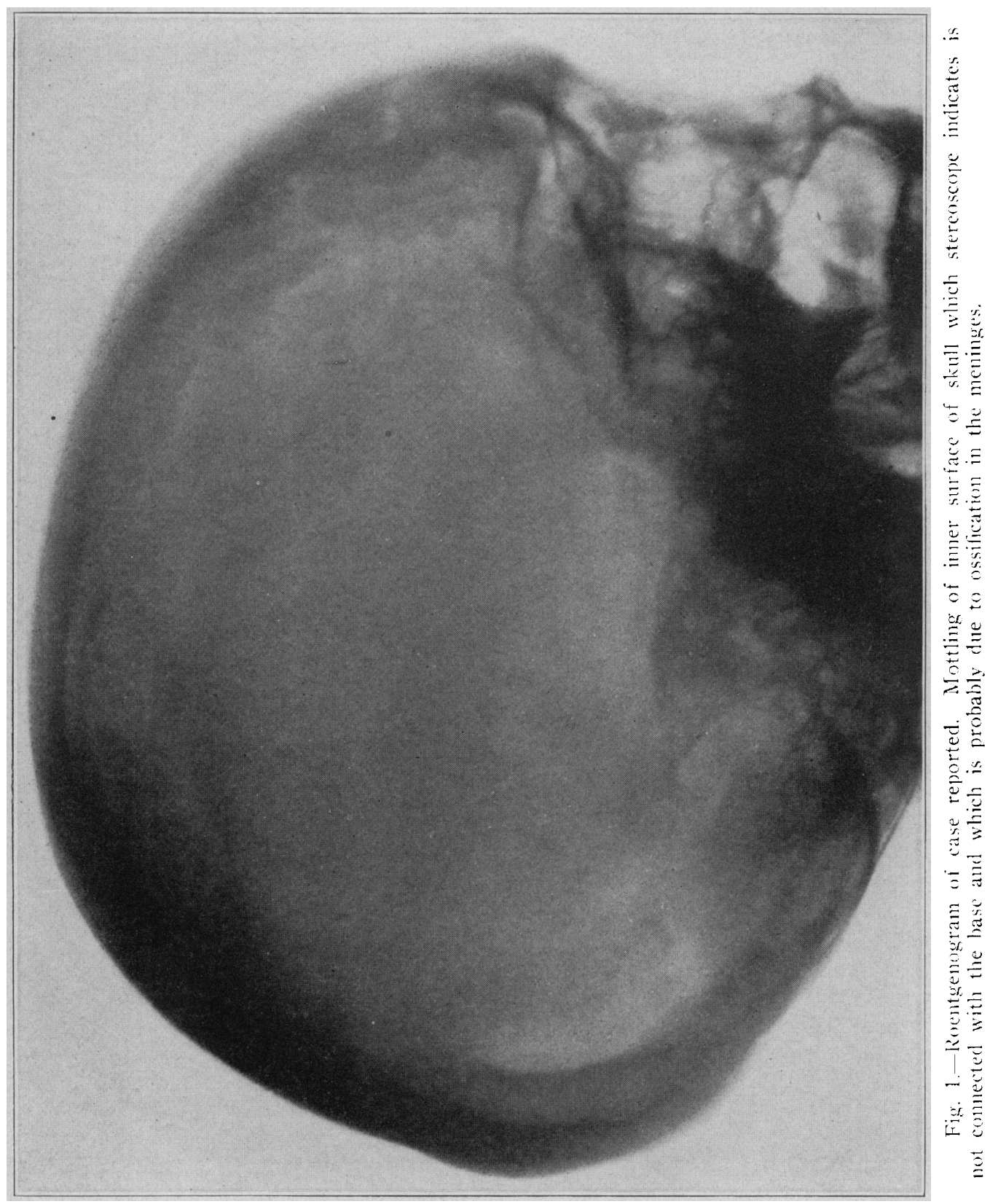


repair failed twenty-five years ago because the pulse became so weak under the anesthetic that the surgeon could not continue the operation. There was a vague possibility that a miscarriage occurred twenty-three years ago.

Present Illness.-Since her pregnancies the patient had not been as well as formerly, but during the past ten years especially she had suffered severely with the symptoms enumerated. The care of her mother who died eight years ago had involved a great deal of anxiety and responsibility.

The vomiting spells first occurred about nine years ago at a time when the patient was acutely anxious concerning her son's health. Since that time they had been fairly constantly present, sometimes occurring every day for perhaps two weeks, with free intervals of several weeks occasionally. Three months had been the longest interval during which she had not vomited. Nausea usually preceded the attacks. They occurred during sleep as well as at any time of day. They bore no relation to the taking of foon. They were occasionally so severe and prolonged that the patient fell asleep from sheer exhaustion. Walking and exercise in general had repeatedly increased the frequency of her attacks. Excitement had never precipitated them.

The headaches described as neuralgic in type, usually but not always unilateral, had persisted for years. There was no periodicity in their appearance, but they were always present at the menstrual periods as well as at other times. The usual location was frontal, with dull aching and drawing pain sometimes referred to the face and throat. Excitement had frequently precipitated and intensified them. The patient also described "sick headaches" associated with vomiting which she characterized as quite different from the neuralgic type.

Insomnia had existed during the same period of years. Five hours was the average amount of sleep obtained. The lack of endurance and languor had been most troublesome and had led to very much circumscribed activities. They have never yielded to the effects of tonic stimulation.

The general physiologic status was good. The bowels were regular. There was frequency of micturition but never incontinence. Digestion, excluding the vomiting attacks, was normal. There had been no especial change in weight during the past ten years.

Examination.-Abnormal Attitudes and Deformities: There were no abnormal attitudes. There were no deformities, except a webbing of the second and third toes of each foot.

Gait: This was normal in all its phases. Associated movements were normal.

Coordination: Equilibratory: Standing with feet together was done well with eyes open and closed. The patient stood on one foot poorly, right and left.

Nonequilibratory: Finger to nose tests were done well, right and left, with eyes open and closed. Finger to finger, and each finger to thumb tests were normalty performed. Heel to knee tests were normal. There was no real adiodokokinesis, but the movements of the left upper extremity were awkward compared with those of the right. There was no dysnuetria.

Skilled Acts: There was no apraxia. Handwriting was normal. Speech was entirely normal.

Abnormal Involuntary Movements: There was slight digital tremor on each side, greater on the left than on the right. There were no twitchings, choreiform movements or other subnormalities. 


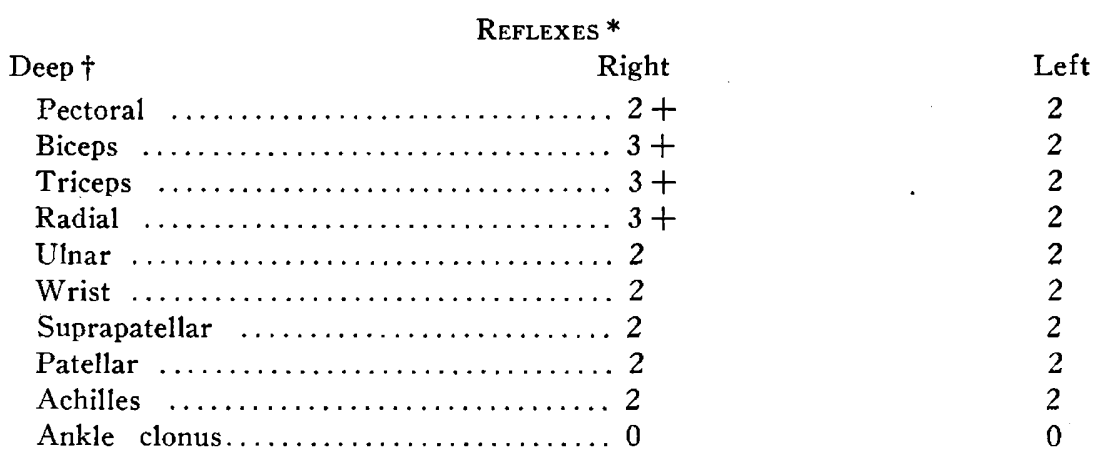

\section{Superficial}

Ciliospinal $\ldots \ldots \ldots \ldots \ldots \ldots \ldots \ldots \ldots 1,1$

Supra-umbilical $\ldots \ldots \ldots \ldots \ldots \ldots \ldots \ldots 1$

Supra-pubic $\ldots \ldots \ldots \ldots \ldots \ldots \ldots \ldots \ldots 1,1$

Upper lateral abdominal .............. 1

Lower lateral abdominal ............... 1

Plantar flexion ...................... 1

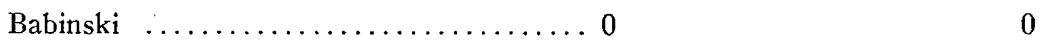

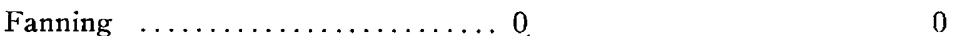

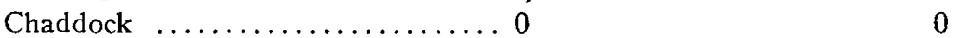

Oppenheim ................... 0

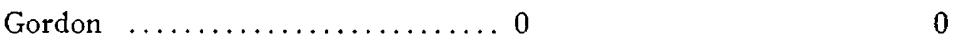

Schäfer ..................... 0

*0-absent. 1-present. 2-active. 3-very active.

$\uparrow$ The deep reflexes have been repeatedly examined on several occasions, and the same inequality has been definitely and invariably found.

Muscle Strength: In all muscle groups muscle strength was much below the average normal. There was, however, no disparity between the two sides that could be determined. The weakness was noticed particularly in the fingers, wrist and forearm muscles, especially in opposed flexion and extension.

Muscle Status: Volume and contour were normal. There was no atrophy or hypertrophy. The consistency was soft and flabby. The tone was normal. There was no perceptible myotatic irritability or myoidema. Electrical tests were not made.

Abnormal Associated Movements: There was a definite Hoffmann sign on the left constantly. It was obtained on the right at times

General Sensory Examination: Touch: Acuity, localization and discrimination were normal throughout. Pain: Superficial and deep pain were normal. Temperature: Moderate degrees of heat and cold were accurately determined. Vibration: Vibratory sensation was normal in the upper and lower extremities. Muscle-tendon: The sensibility was normal in the toes, fingers, forearms and arms.

Stereognosis: The size and form of objects were correctly noted.

Cranial Nerves: Optic, Oculomoter, Trochlear and Abducens Nerves and Optic Apparatus: Visual acuity was not tested. The fields were normal to 
rough tests. The fundi were normal; the pupils were equal, regular, central and moderately dilated. They responded briskly to light and convergence. There was no strabismus. no ptosis, no nystagmus, no exophthalmus or enophthalmus.

Acoustic and Ear: Acuity of hearing was normal for a watch tick. Air conduction was better than bone conduction on both sides. The Rinne test was normal.

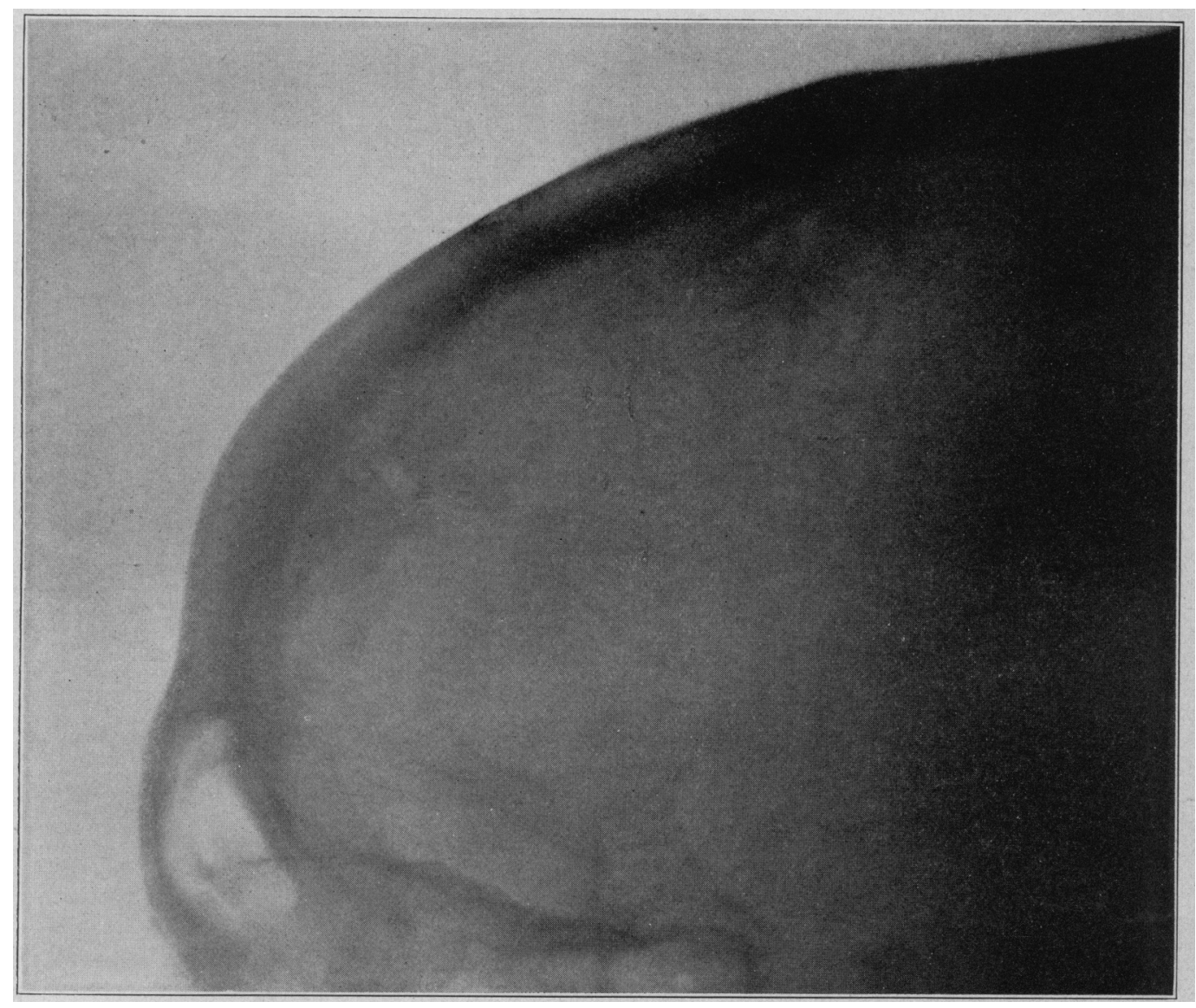

Fig. 2.-Case not accessible to clinical study showing similar osseous changes. Areas of meningeal density which are probably due to ossification.

Trigeminus and Mouth: The motor fifth nerve was normal. The corneal reflex was brisk on each side. There were no ahnormalities of the mouth or of the teeth worthy of note.

Facial Nerve and Face: In conversation there was a marked weakness of the lower two thirls of the left side of the face. In smiling this weakness was still apparent. In forced movements, however, such as showing the teeth, and in hearty laughter the weakness was no longer manifested. 
Articulation of the lalials was normal. Associated movements of the face, eyes and head were normal.

Glossopharyngeus, Vagus Nerves, Pharynx and Larynx: Taste was not examined, but was probalily normal. The uvula was normal in position and rose in midline to phonation. Palatal and pharyngeal reflexes were normal. Phonation and swallowing were normal.

Spinal Accessory Nerve: No alunormality in the function of the trapezit or sterno-cleido-mastoids could be eliciced.

Hypoglossal Nerve and Tongue: The tongue protrucled in the midline: it moved well in all directions and presented no trophic disturbances.

Mental Status: The patient was of an extremely intelligent type. She was alert, of a genial disposition and decidedly not introspective. Her mental life was one filled with cletailed care and management of her family and home

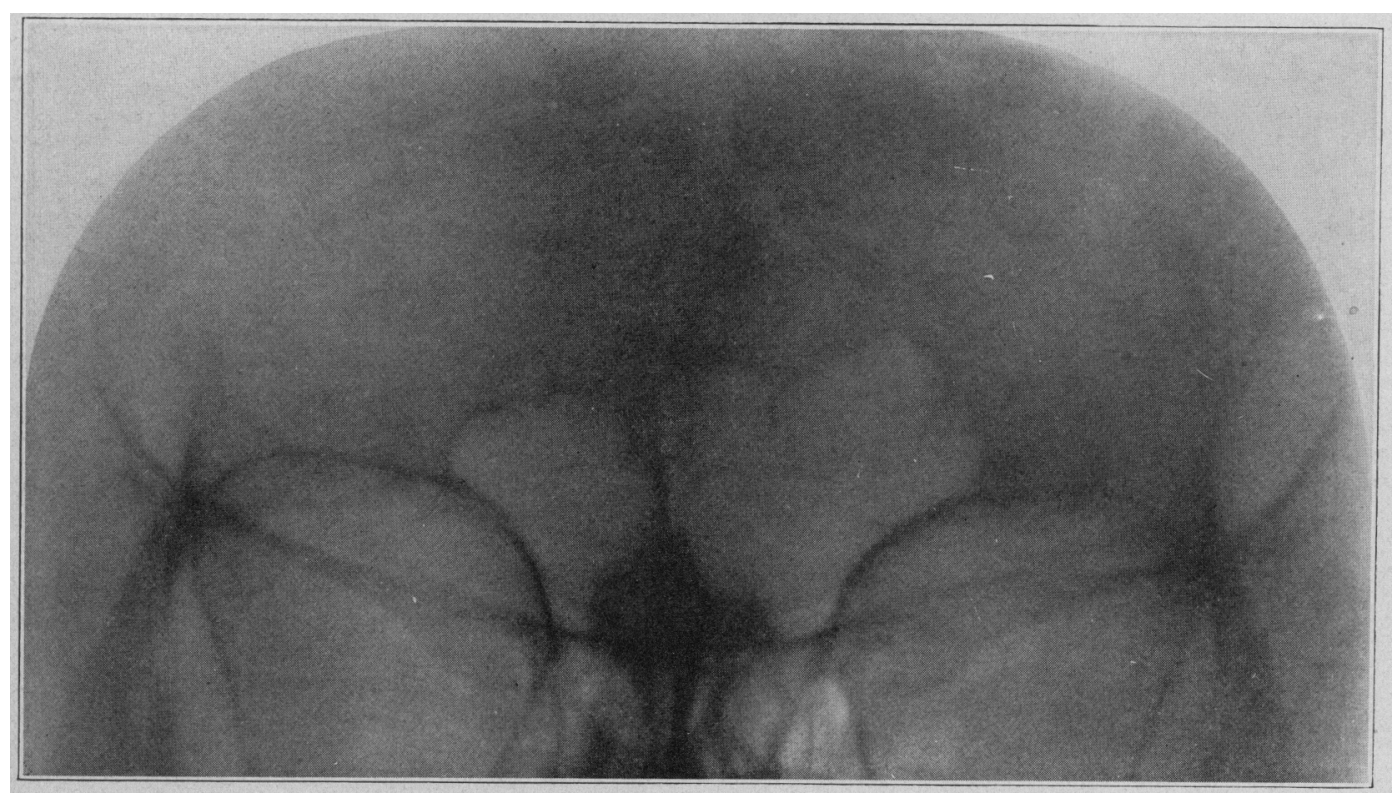

Fig. 3.-Distrihution of these ossifications through the frontal areas.

affairs. She was not irritable, in the ordinary sense, although the usual disturliances of a large household were frequently a source of annoyance which she did not express externally. There was no emotional instability. In fact, the patient's hushand considered her especially well balanced. Attention and memory were not defective. There were no pholias, compulsions, hallucinations or Celusions.

Cranial Morphology: The skull was normal to palpation. There harl been no noticeahle increase in size.

Systemic Examination: Tegumentary: Her hair was normal in color, amount, texture and distrilution. There was no pigmentation of the skin or vasomotor disturbances of any kincl. Adipose tissue was rather excessive, but evenly distributed. 
Glandular: The thyroid gland was normal. The tonsils were small and almost invisible. There was no palpable adenopathy.

Cardiovascular: The heart was normal. Systolic pressure was 130 . The pulse rate was variable, averaging 80 .

Respiratory: The lungs were normal.

Gastro-lntestinal: The liver and spleen were not palpable. Palpation and percussion was otherwise normal. (See roentgen-ray report.)

Genito-Urinary: The patient had a rather excessive leukorrhea, but no pelvic signs or symptoms. As stated in the foregoing, micturition was sometimes urgent.

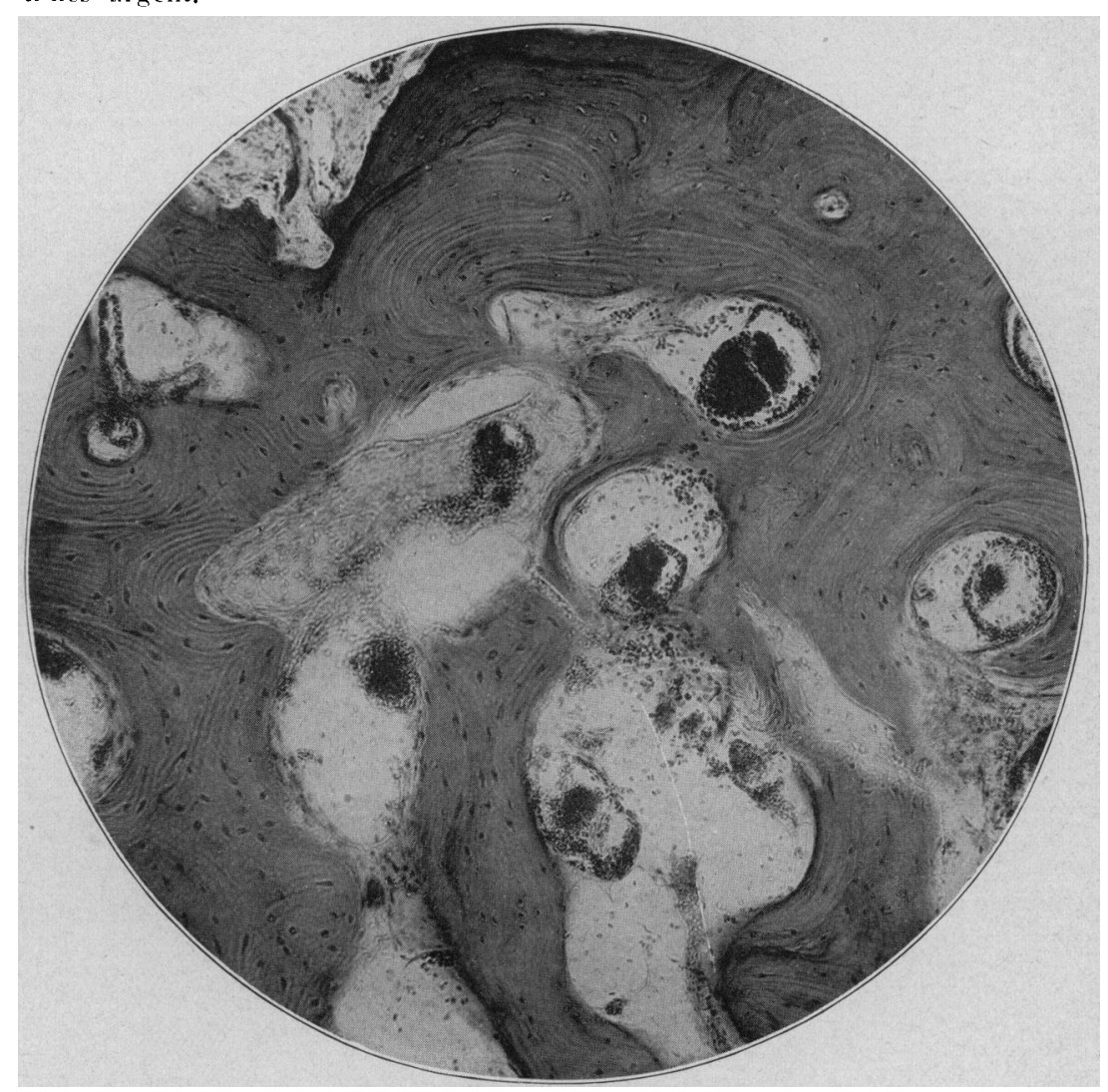

Fig. 4--Section of osteophyte of the falx cerebri. Specimen submitted by the courtesy of Dr. J. H. Larkin, pathologic department, City Hospital.

Iaboratory Examination.-Urine Analysis: The findings were: appearance, very turbicl; color, pale amber; reaction, acil; specific gravity, 1.028; albumin, trace; sugar, absent; acetone, absent: diacetic acid, absent; indican, normal; urea, 2.4 per cent.; bile pigments, absent; blood pigments, absent.

Microscopic Examination: The examination relealed: casts, none; cylindroids, none; mucus, a few threads; amorphous, fow urates; crystals, none: pus, a few cells; red blood cells, none: bacteria, numerous motile hacilli (contamination); epithelia, few squamous cells. 
Blood Wassermann Reaction: The extracts used were crude alcoholic and cholesterinized. The result was negative.

Blood Chemistry: The following determinations were made in 100 c.c. of blood: uric acid, $3.2 \mathrm{mg}$; urea nitrogen, $18 \mathrm{mg}$; urea, $39.5 \mathrm{mg}$; ; creatinin, 2.6 mg.; sugar, $125 \mathrm{mg}$. or 0.125 per cent. The examination showed slight nitrogenous retention and hyperglycemia.

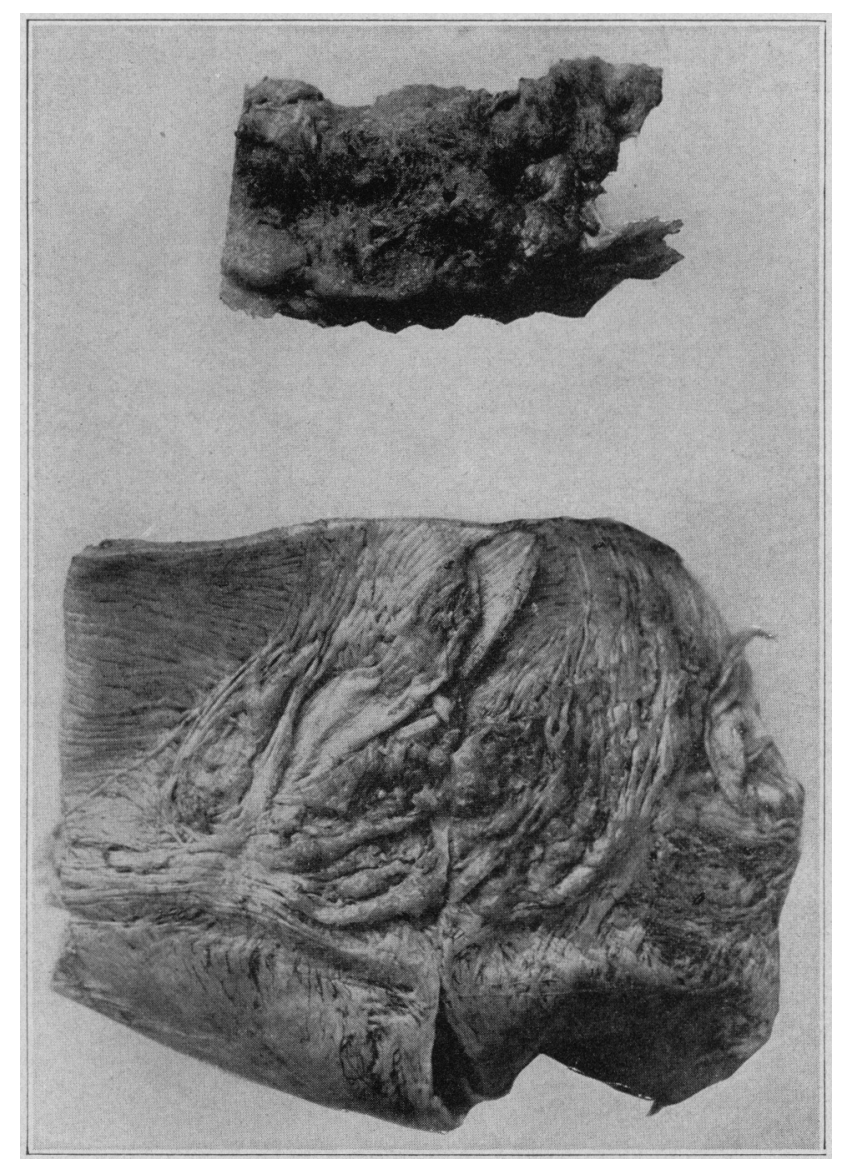

Fig. 5.-Osteophytes of the dura, near superior longitudinal sinus. Note jagged contour of internal surfaces. Microscopic examination revealed true bone. Specimen submitted by courtesy of Dr. Douglas Symmers, Director of Laboratories, Bellevue Hospital.

Complete Blood Count: The blood count revealed: erythrocytes, 4,200,000 per cubic millimeter; leukocytes, 6,000 per cubic millimeter; hemoglobin, 76 per cent.; color index, 0.9 per cent. Differential Leukocyte Count: polymorphonuclear neutrophils, 59 per cent.; small lymphocytes, 38 per cent.; large lymphocytes, 0 ; large mononuclear letkocytes, 0 ; transitional leukocytes, 1 per cent.; eosinophils, 2 per cent.; basophils, 0 . 
The examination revealed a moderate diminution in the percentage of hemoglobin and in the number of red corpuscles, with a fair number of leukocytes and practically a normal differential count.

The red corpuscles were quite uniform in size and shape.

Gastro-Intestinal Serial Roentgen-Ray Taken 1913: Roentgenograms showed residue after six hours. The pylorus was apparently filled out properly. The cecum was rather low, the stomach high.

Skull: Roentgen-ray examination of the skull showed it to be of normal size with a slight increase in its thickness and density. The outer surface seemed to be quite normal, but the inner surface of the frontal and parietal regions was definitely roughened. Stereoscopic plates as well as the anterior ones showed that this was not confined to the longitudinal sinus but was distributed over the entire frontal bone and over an irregular area in the parietal. The stereoscope would further indicate that these processes were of about the same density as the bone and that they projected into the cavity. The sella was not disturbed, and there were no indications of increased intracranial pressure.

Summary of Essential Findings.-These were: history of headaches over a period of nine years; vomiting, occurring at any time of night or day at irregular intervals, aggravated by exercise; pathologically increased deep reflexes of the right upper extremity and bilateral Hoffmann's sign; facial weakness of the central type on the left; roentgenogram of the skull revealed extensive ossification of the meninges.

In a careful and prolonged study of the patient we have been convinced that the signs and symptoms described in the foregoing are due directly to the pathologic condition of the meninges. All other abnormal changes in the skull that might simulate meningeal ossification, including syphilis, carcinoma, tuberculosis and Paget's disease have been easily eliminated.

While our belief that meningeal ossification can be diagnosed during life has not yet been substantiated by postmortem confirmation in this case, it is our conviction that careful investigation in this direction will prove ultimately the occasional clinical importance of this phenomenon.

\section{DISCUSSION}

Dr. BeverLey R. Tucker of Richmond said that he thought this presentation was of great interest, and he briefly reported a case of ossification of the spinal meninges.

About four years ago he had seen the patient and made a diagnosis of spinal tumor, although the central level was quite indefinite. Her pain, however, was severe and radiated around her body. She had a spastic paraplegia which seemed to be progressive. Her symptoms dated back for about a year. A radiograph of the whole spinal region failed to show anything unusual. Dr. Tucker supposed that it was possibly harder to pick up. plaques of this kind on the cord meninges than it was on the brain. Dr. Stuart McGuire of Richmond operated on the patient, and, much to their surprise, found ossified plaques-some of them separate and some overlapping. They were a little larger than the little finger nail; however, some were larger and some were 
smaller. They exposed an area of about three and a half vertebrae, and although ten of these plaques were removed, they felt that they had not removed all of them. The case was closed up and the patient had been under his observation ever since. He thought the interesting part of it was that the spastic paraplegia had progressed and seemed to have extended up the cord. The spinal cord in the region of most of the plaques had dwindled to about half of its size, showing atrophy; it took on a conelike shape. The specimens of these plaques were sent to the laboratory and were reported as cartilage or bone.

It had been about four years since the operation and one arm was considerably involved by pain and some disturbance of motion, and the other arm was slightly involved. This woman had never shown any cerebral symptoms, as far as they could elicit. He had hesitated to advise operation but had a surgeon examine her with a view to the possibility of another operation to remove more of these plaques, but the prognosis seemed so uncertain that nothing had been done.

Dr. ERNest SACHs of St. Louis said that these ossifications were particularly interesting to him because of the great difficulty of differentiating endothelioma, which are known not infrequently to come from the dura and which not infrequently present a picture similar to those which are seen with ossification, and he would be very much interested to know whether Dr. McKendree could throw some light on how to differentiate these ossifications from ossified endothelioma.

He had operated on two patients, in both of whom he and Dr. Moore, the otologist, believed that there was more of a tumor than the calcification in the dura.

Dr. Charles A. Elsberg of New York said that the Association ought to be much indebted to Dr. McKendree for having brought forward this interesting subject. He had been interested and often much worried because he had seen so many ossifications and calcifications in the meninges and had not understood their significance. He had asked himself whether they could give rise to symptoms.

In many instances of degenerative disease of the central nervous system, and especially in atrophic spinal cords, these calcified plaques often exist in large numbers. There may or may not be a history or the evidence of trauma. The question was whether these calcifications were not entirely secondary to the disease of the nervous system and whether they could give rise to symptoms or influence the changes in the diseased nerve tissue.

Dr. Charles A. MCKendree of New York, in closing, said that in reading the literature of the subject, he had found ossified and calcified plaques of the spinal meninges mentioned frequently. Also, in the lower animals, especially the dog, progressive spinal paralysis attributed to ossification of the dura and pia-arachnoid had been reported by French veterinarian schools.

In discussing the matter with several prominent pathologists he had learned that they were commonly encountering ossified areas in the spinal membranes, but that these lesions were not very extensive and did not have the characteristics of depth and penetration that the cerebral plaques had. Therefore, he would be surprised, in general, to find that they could be as significant in man as the cerebral ossifications.

With reference to Dr. Sachs' question as to endotheliomas, he would say that in the case reported there were none of the usual signs of increased intracranial pressure. The symptoms had endured for at least ten years, and the findings could not justify the diagnosis of cerebral neoplasm. 